\title{
Brexit para Dummies
}

Por Eduardo Leyton Guerrero,

Director de Carrera Contador Público Auditor, Universidad Alberto Hurtado

\section{Guía rápida para comprender cómo una gran potencia económica-militar como el Reino Unido (UK), abandona uno de las comunidades más exitosas de la historia de nuestra civilización.}

\section{INTRODUCCIÓN}

R ecordemos que el año 1957, con el Tratado de Roma y con la suscripción de países como Alemania, Francia, Italia, Bélgica, Países Bajos y Luxemburgo, se dio inicio a la Comunidad Económica Europea (CEE). Desde esa fecha, el bloque europeo sistemáticamente logró niveles de industrialización en todos los ámbitos que permitió el crecimiento económico para una Europa todavía golpeada por la segunda guerra mundial. Hoy, para el mundo entero, es un ejemplo concreto de cómo avanzar mirando al futuro y no al pasado. En ese contexto, trataremos de comprender las principales causas que dieron origen a la salida del UK de este exitoso bloque.

\section{¿Qué es el Brexit?}

En términos sencillos, Brexit es el término con el que se denomina la voluntad de Gran Bretaña de abandonar la CEE. BR viene de British y EXIT significa "salir". Este proceso se inició con una consulta (plebiscito si fuera en Chile) a todos los ciudadanos del Reino Unido en la que se les pregunto si estaban a favor o en contra de abandonar la CEE. Hubo líderes que apoyaban una y otra posición, pero finalmente venció la opción de salida. El término de este proceso se estima en un plazo máximo de 2 años. Un hito importante ha sido la salida del Primer Ministro David Cameron, a cambio de la Ministra Theresa May, quien liderará el proceso con el objeto de minimizar los efectos negativos en UK. No podemos dejar de mencionar que su homóloga alemana Angela Merkel, aduciendo la representación de la CEE, exigirá una pronta salida.
Antecedentes Pre-Brexit: La victoria de la Comunidad Económica Europea (CEE)

Para nadie es un misterio que, en general, el todo es mejor que la suma de las partes. Este un principio básico que proviene de la teoría general de sistemas: sinergia. La Comunidad Económica Europea, Comunidad Europea Zona Europea o como se le denomine, fue y es un gran logro de civismo de toda nuestra civilización. Especialmente después de 
dos monstruosas guerras mundiales, en donde el campo de batalla fueron sus mismas calles y casas. Los logros de la CEE, entre ellos, para frenar en su oportunidad al bloque soviético y para generar confianza al alero del occidente es indesmentible. Esto ha resultado en varias décadas de paz, cerrando la era de la guerra fría. La CEE fue una de las piezas fundamentales para detener la exportación del comunismo intervencionista y no olvidar, para hacer frente en las últimas décadas, al gigante de EEUU y hoy, a la Gran Muralla China.

En otro escenario digno de destacar es el avance en las ciencias naturales. La medicina, la ingeniería genética, las ciencias físicas y astronómicas (organización E.S.O. en donde Chile es parte importante) y la astronáutica (organización E.S.A.) por nombrar algunas, se vieron inmensamente potenciadas por esta conjunción de cerebros europeos facilitada por la integración. El mismo Stephen Hawking, físico teórico, lo advertía antes de la votación; lo que pierde en el campo de las ciencias el Reino Unido con el Brexit, es inconmensurable e imposible de transmitir a una masa de votantes. En lo personal, el Reino Unido perdió uno de sus hemisferios del cerebro, ya veremos cuál de los dos lados. Uno de los grandes logros de esta magna integración científica es el gran laboratorio de física LHC (The Large Hadron Collider) del CERN, cuyos resultados permitirán sustentar la nueva física, especialmente la mecánica cuántica que se prevé traerá beneficios inconmensurables a nuestra civilización.

Por otro lado, el libre tránsito, catalizador por cierto la gran industria del turismo, la colaboración policial, han sido fundamentales para enfrentar un nuevo embate y forma de "hacer" terrorismo.

Para países como Chile, sería una bendición del Gran Arquitecto pertenecer a una comunidad tan avanzada y selecta como la CEE. Específicamente me refiero a la mirada de futuro con que gestiona su parlamento europeo y cómo se proyectan en todos los ámbitos para los próximos decenios.

En fin, existen evidencias claras de los extraordinarios beneficios de esta integración.

\section{Si la integración ha sido tan positiva, entonces ¿Por qué gano el Brexit?}

\section{Nacionalismo}

Cuesta entenderlo al comienzo, y por eso trataré de explicarlo desde mi perspectiva. Cualquier líder o grupo político al usar las típicas herramientas populistas como por ejemplo: gobernar con slogan, cuestión muy de moda en el Chile de hoy; o sencillamente recurrir a nacionalismos; o creer o sentirse superior al resto despierta grandes apetitos independentistas en el electorado y son catalizadores para que grupos o líderes políticos, que llevan la "guaripola" de estas ideas, muevan a sus votantes. En efecto, la incubación del Brexit fue precisamente hecha con estos instrumentos. Pero falta algo.

¿Qué motivo al electorado?, ¿Qué lo sedujo?¿Qué lo hipnotizo para tomar tan drástica decisión?

\section{Costo económico del apoyo a naciones menos desarrolladas}

En mi opinión, la subsidiaridad como práctica constante de "sostener" a las economías menos rigurosas por parte de las más disciplinadas a un costo alto para éstas. Por ejemplo España y específicamente Grecia fueron los triggers de este creciente malestar del UK. Otro factor fue el ingreso de nuevos países a la CEE cuyas economías, aun frágiles, podrían ser a futuro nuevos escenarios de grandes ajustes. Como decimos en Chile, el UK se cansó de llevar a la "Cochiguagua" a los más lentos, a los que les gusta la farra y después que pague "Molla".

Costos de la inmigración desregulada Otro elemento es la inmigración. Con todo lo que ello implica, desde la importación de pobreza, choques culturales, terrorismo, etc. Por cierto, este es un fenómeno humano devastador que nuestra sociedad occidental no puede hacer frente de manera racional. Es uno de los símbolos negativos del sistema económico, que muchos detractores del liberalismo económico aprovechan para horadarlo en todos sus ámbitos, olvidando eso sí, los grandes logros de éste. Podemos discutir en otra oportunidad sus beneficios y sus horrores. Peros sigamos.

¿Porque una sociedad que ha hecho grandes sacrificios por siglos haciendo bien la cosas, siendo austeros, ordenados, viviendo penurias y postergándose en muchos aspectos, cuando logra su pleno desarrollo tiene que aceptar a otros que histórica y sistemáticamente lo han hecho mal? Estoy seguro que muchos tendrán grandes y variados argumentos para justificar la inmigración; desde la solidaridad, la humanidad, los derechos humanos, todos ellos muy buenos argumentos y que en gran parte suscribo. Pero, entonces ¿Que motivación tiene una persona y una sociedad para hacer bien las cosas? ¿Por qué los que son los líderes de esos pueblos éxodos no se civilizan y hacen bien su gestión país? ¿Cuál es el beneficio del UK o de cualquier otro país que se sacrifica por el futuro, si continuamente tengo que estar subsidiando al que no lo hace?

A mi entender, este es otro de los grandes motivos que permitió que germinara el Brexit que junto a las herramientas populistas, fue solo un bálsamo para éxito del Exit.

Con esos motivos, hasta yo, si fuera de UK votaría por el Brexit! 